\title{
Effects of partial replacement of soybean meal with roasted guar korma and supplementation of mannanase on performance and carcass traits of commercial broiler chickens
}

\author{
Abhijit Mishra, Samir Kumar Sarkar, Subhasish Ray and Sudipto Haldar
}

Department of Research and Development,

Amrit Feeds Ltd., Infinity Benchmark Block EP and GP, Sector V Salt Lake, Kolkata - 700091, West Bengal, India

Corresponding author: Sudipto Haldar, email: sudipto.haldar@amritgroup.net

Received: 28-03-2013, Revised: 23-05-2013, Accepted: 25-05-2013, Published online: 20-07-2013

doi: 10.14202/vetworld.2013.693-697

How to cite this article: Mishra A, Sarkar SK, Ray S and Haldar S (2013) Effects of partial replacement of soybean meal with roasted guar korma and supplementation of mannanase on performance and carcass traits of commercial broiler chickens, Veterinary World 6(9): 693-697

\begin{abstract}
Aim: To evaluate the effects of inclusion of roasted guar meal, also known as guar korma, as a partial replacement for deoiled soybean meal (SBM) in commercial broiler diets, on production performance and carcass traits of Cobb-400 broiler chickens.

Materials and Methods: 1600 one-day-old Cobb-400 broiler chicks were randomly assigned into four dietary treatments, each with four replicates ( $\mathrm{n}=100$ chicks per replicate). The diets were iso-nitrogenous and iso-caloric and included the basal diets composed of maize and SBM (T0), T0 + $\beta$-mannanase (T1) and the treatment diets in which SBM was partially replaced $(20 \mathrm{~g} / \mathrm{kg}$ in pre-starter, $50 \mathrm{~g} / \mathrm{kg}$ in starter and finisher) with guar korma (T2) and T2 $+\beta$-mannanase (T3).

Results: Live weight was unaffected by the dietary treatments $(\mathrm{P}>0.05)$. Guar korma increased feed intake when compared with the SBM fed groups $(\mathrm{P}=0.01)$. Feed conversion was better $(\mathrm{P}=0.01)$ when $\mathrm{SBM}$ was fed to the chickens irrespective of mannanase supplementation. As a consequence the performance index score was superior $(\mathrm{P}=0.04)$ in the SBM fed groups when compared to the guar korma fed groups. Across the diets, feed conversion was superior $(\mathrm{P}<0.05)$ in the T1 group suggesting a beneficial effect of $\beta$-mannanase in the maize-SBM diet. Dressed yield showed a trend to improve $(\mathrm{P}=0.08)$ upon $\beta$-mannanase supplementation.
\end{abstract}

Conclusion: It was concluded that partial replacement of SBM with guar korma may not yield any substantial benefits in terms of performance and carcass traits and that supplementation of $\beta$-mannanase may also not be worthwhile in alleviating the negative effects of guar korma.

Keywords: $\beta$-mannanase, broiler chickens, carcass traits, guar korma, performance

\section{I ntroduction}

Guar (Gyamopsis tetragonoloba) is a drought resistant annual legume predominantly grown in India and Pakistan [1]. The plant is primarily grown for its galactomannan polysaccharide gum which has numerous industrial and food processing applications [2]. Guar meal is the main by-product of guar gum production with a protein content of approximately 380 $\mathrm{g} / \mathrm{kg}$ [3]. It is a mixture of germs and hulls at an approximate ratio of $25 \%$ germ to $75 \%$ hull [4]. The high amino acid content of the guar meal protein makes it a useful protein supplement for broilers and layers. Since the germ fraction of guar meal contains energy, protein, methionine and phosphorus in higher levels than that in soybean meal (SBM), addition of guar meal as a partial replacement $(<10 \%)$ of SBM in poultry diets may be a useful economic strategy for decreasing feed costs without any negative effects on production [5]. However, some of the anti-nutritional agents (trypsin inhibitors, gum residue, saponins) present in guar meal limit its usage at high levels in broiler diets

This article is an open access article licensed under the terms of the Creative Commons Attribution License (http://creativecommons. org/licenses/by/2.0) which permits unrestricted use, distribution and reproduction in any medium, provided the work is properly cited.
[6]. The deleterious effects attributed to the trypsin inhibitors [7], have been an issue of contradiction because it was reported that guar meal contained lower levels of trypsin inhibitor than processed SBM $[8,9]$. Therefore, growth inhibition that follows the addition of guar meal in diet may be attributed to the residual gum content of the meal $[10,11]$. The residual gum, due to its sticky nature, increases intestinal viscosity and decreases nutrient absorption from the small intestine [12,13]. One of the methods to ameliorate the negative effects of the galactoamannan content of guar meal is to supplement the diet with the $\beta$-mannanase enzyme. $\beta$-mannanase hydrolyses the galactomannan complex of guar meal. As a result the guar gum induced viscosity in digesta is reduced, which increases the digestibility of starch $[14,15]$ and improves the metabolizable energy of guar meal. In this way $\beta$ mannanase supplementation helps in achieving superior feed conversion and better growth performance in broilers fed with guar meal $[16,17]$. The objective of our current research was to evaluate the effects of inclusion of roasted guar meal, also known as guar korma, as a partial replacement for SBM in commercial broiler diets on production performance and carcass traits of Cobb- 400 broiler chickens. 
Available at www.veterinaryworld.org/Vol.6/Sept-2013/21.pdf

Table-1. Composition of the basal and experimental diets (in $\mathrm{g} / \mathrm{kg}$ unless stated otherwise).

\begin{tabular}{|c|c|c|c|c|c|c|}
\hline & \multicolumn{2}{|c|}{ Pre starter } & \multicolumn{2}{|c|}{ Starter } & \multicolumn{2}{|c|}{ Finisher } \\
\hline & T0/T1 & T2/T3 & T0/T1 & T2/T3 & T0/T1 & T2/T3 \\
\hline Dry matter & 905 & 910 & 904 & 909 & 912 & 907 \\
\hline Energy kcal/kg* & 3002 & 3000 & 3112 & 3115 & 3141 & 3147 \\
\hline Crude protein & 222 & 222 & 203 & 202 & 185 & 188 \\
\hline Ether extract & 36 & 39 & 53 & 50 & 44 & 46 \\
\hline Crude fibre & 44 & 46 & 43 & 45 & 41 & 44 \\
\hline Salt & 3.8 & 4.0 & 4.1 & 4.3 & 3.9 & 4.2 \\
\hline Calcium & 9.1 & 9.1 & 8.6 & 8.7 & 8.6 & 8.5 \\
\hline Available P* & 5.2 & 5 & 4.8 & 4.7 & 4.7 & 4.6 \\
\hline
\end{tabular}

* Calculated values

T0, control diets containing maize and soybean meal; T1, T0 + $\beta$-mannanase ( 32 million units/kg of feed); T2, Soybean meal replaced by guar korma at the rate of $20 \mathrm{~g} / \mathrm{kg}$ in the pre starter and $50 \mathrm{~g} / \mathrm{kg}$ in the starter and finisher diets; T3, T2 + $\beta$-mannanase ( 32 million units/kg of feed)

\section{Materials and Methods}

Ethical approval: This research work was carried out as per the guidelines in force at the time of carrying out the experiment.

Bird husbandry: A straight run flock of one-day-old Cobb-400 broiler chickens $(\mathrm{N}=1600)$ with an average body weight of $43.5( \pm 1.19) \mathrm{g}$ were assigned to four dietary treatments for 35 days. Each treatment group had four replicates with 100 birds in each replicate. The replicates were housed in pens $(3.2 \mathrm{~m} \times 3.2 \mathrm{~m})$ on litter composed of saw dust and wood shavings. All birds were vaccinated against Newcastle disease (on days 5 and 20) and Infectious bursal disease (on day 13). Bird management was according to the recommendations of Cobb Management Guide [18]. The chicks received the designated treatment diets within $12 \mathrm{~h}$ of their hatching. The dietary ingredients included maize, SBM, meat and bone meal, de-oiled mustard cake, vegetable oil, lime stone powder, di-calcium phosphate, common salt, vitamin premix, trace minerals and other additives which are normally used in standard commercial broiler diets. The diets were categorized as pre-starter (day 1-14), starter (day 15-28) and finisher (day 29 till harvesting). The composition of the diets is presented in Table-1. All chickens had ad libitum access to feed and drinking water.

Dietary treatments: The dietary treatments were as follows: a maize and de-oiled SBM based control diet (T0), T0 supplemented with the $\beta$-mannanase enzyme (T1) and treatment diets in which SBM was replaced partially $(20 \mathrm{~g} / \mathrm{kg}$ in pre-starter and $50 \mathrm{~g} / \mathrm{kg}$ in starter and finisher diets) with roasted guar korma (T2) and T2 supplemented with the $\beta$-mannanase enzyme (T3). The activity of the supplemental $\beta$-mannanase enzyme was 32 million units $/ \mathrm{kg}$ feed. The diets were formulated on an iso-nitrogenous and iso-caloric basis.

Performance and carcass traits: The birds were monitored every day for signs of any disease and mortality. Live weight (LW) of individual chickens was recorded at 14, 28 and 35 days of age and the data were pooled pen-wise. Daily feed consumption was recorded pen-wise and terminal feed conversion (corrected to $2 \mathrm{~kg} \mathrm{LW}$ ) was calculated for each pen on the basis of cumulative (1-35 day) feed consumption.
Mortality, if any, was recorded and liveability of the experimental flock was calculated for each experimental group.

On day 35, 4 birds ( 2 males and 2 females) having LW close to the mean LW of the pen were selected for determination of carcass traits. The chickens were mechanically stunned followed by exsanguination. The carcasses were defeathered and eviscerated. The dressed carcass weight was determined after complete removal of organs and gastro intestinal (GI) tract. Internal organs (heart, liver and spleen) and gizzard were severed out and washed with phosphate buffered saline to remove blood and tissue debris. Giblet weight was expressed as the combined weight of heart, liver and gizzard. Liver and spleen were also weighed separately. The entire GI tract was removed, soaked in phosphate buffered saline to remove the blood and tissue debris, weighed and the length was measured. All the measurements were expressed as $\mathrm{g} / \mathrm{kg}$ of LW except the length of the GI tract which was expressed in $\mathrm{cm}$.

day 35, 4 birds (2 males and 2 females) having LW close to the mean LW of the pen were selected for determination of carcass traits. The chickens were mechanically stunned followed by exsanguination. The carcasses were defeathered and eviscerated. The dressed carcass weight was determined after complete removal of organs and gastro intestinal (GI) tract. Internal organs (heart, liver and spleen) and gizzard were severed out and washed with phosphate buffered saline to remove blood and tissue debris. Giblet weight was expressed as the combined weight of heart, liver and gizzard. Liver and spleen were also weighed separately. The entire GI tract was removed, soaked in phosphate buffered saline to remove the blood and tissue debris, weighed and the length was measured. All the measurements were expressed as $\mathrm{g} / \mathrm{kg}$ of $\mathrm{LW}$ except the length of the GI tract which was expressed in $\mathrm{cm}$.

The Performance Index Score (PIS) was calculated using the following formula.

PIS $=\frac{\text { Percentage of liveability XAverage final live wt. }(\mathrm{kg})}{\text { Age of experimental birds } \times \text { Feed conversion Ratio (FCR) }} \times 100$

Chemical analysis: Feed samples were analyzed for dry matter, crude protein ( $\mathrm{N} \times 6.25)$ crude fibre and 
Table-2. Effect of guar korma and $\beta$-mannanase on performance.

\begin{tabular}{|c|c|c|c|c|c|c|}
\hline & \multicolumn{3}{|c|}{ Live weight (g) } & \multirow{2}{*}{$\begin{array}{c}\text { Feed intake (g) } \\
\text { (1-35 days) }\end{array}$} & \multirow[t]{2}{*}{ Feed conversion } & \multirow{2}{*}{$\begin{array}{l}\text { Performance } \\
\text { index score }\end{array}$} \\
\hline & Day 14 & Day 28 & Day 35 & & & \\
\hline \multicolumn{7}{|l|}{ Main effect of guar korma } \\
\hline No guar korma & 526.9 & 1432.1 & 1866.5 & 3151.3 & 1.785 & 284.5 \\
\hline $\begin{array}{l}\text { + Guar korma } \\
\text { Main effect of mannanase }\end{array}$ & 539.9 & 1440.5 & 1863.1 & 3361 & 1.934 & 258.5 \\
\hline No $\beta$-mannanase & 529.8 & 1439 & 1875.8 & 3316.4 & 1.882 & 271 \\
\hline $\begin{array}{l}+\beta \text {-mannanase } \\
\text { Dietary effects }\end{array}$ & 537 & 1433.6 & 1853.8 & 3195.9 & 1.837 & 271.9 \\
\hline TO & $529.4^{\mathrm{a}}$ & 1440 & 1872.2 & 3191.1 & $1.812^{\mathrm{ab}}$ & 286.2 \\
\hline $\mathrm{T} 1$ & $544.7^{\mathrm{b}}$ & 1442.9 & 1879.4 & 3111.6 & $1.759^{\mathrm{a}}$ & 282.8 \\
\hline T2 & $524.4^{\mathrm{a}}$ & 1427.1 & 1853.6 & 3441.8 & $1.953^{\mathrm{b}}$ & 255.9 \\
\hline T3 & $535.2^{\mathrm{ab}}$ & 1437.1 & 1854.1 & 3280.2 & $1.914^{\mathrm{ab}}$ & 261.1 \\
\hline Pooled SEM & 2.05 & 7.67 & 16.92 & 33.83 & 0.03 & 5.61 \\
\hline $\begin{array}{l}\text { Coefficient of variation \% } \\
\text { Main effects ( } P \text { values) }\end{array}$ & 1.5 & 2.1 & 3.5 & 4 & 4.9 & 7.5 \\
\hline Guar korma & 0.01 & 0.59 & 0.92 & 0.01 & 0.01 & 0.04 \\
\hline Mannanase & 0.10 & 0.73 & 0.53 & 0.10 & 0.37 & 0.94 \\
\hline $\begin{array}{l}\text { Guar korma x mannanase } \\
\text { ( } P \text { values) }\end{array}$ & 0.59 & 0.77 & 0.91 & 0.56 & 0.89 & 0.71 \\
\hline
\end{tabular}

Means bearing different superscripts in a column differ significantly $(P<0.05)$

T0, control diets containing maize and soybean meal; T1, T0 + $\beta$-mannanase ( 32 million units/kg of feed); T2, soybean meal replaced by guar korma at the rate of $20 \mathrm{~g} / \mathrm{kg}$ in the pre starter and $50 \mathrm{~g} / \mathrm{kg}$ in the starter and finisher diets; T3, T2 + $\beta$-mannanase ( 32 million units/ $\mathrm{kg}$ of feed)

ether extract as per AOAC [19]. Metabolizable energy (ME) was calculated from standard tables of NRC [20]. Calcium and available phosphorus content of the experimental diets were estimated as per the methods described in IS: 7874 [21] and IS: 1374 [22], respectively.

Statistical analysis: All data were pooled replicate wise for analysis. The data were analyzed in a $2 \times 2$ factorial design where the levels (absence and presence) of guar korma and supplemental $\beta$-mannanase were considered to be the two factors. The main effects as well as the interaction between these factors were determined. A multivariate analysis of variance (ANOVA) was performed for analysing the data and the results were expressed as means and pooled standard error of means. The data were also subjected to one way ANOVA for differentiating the effects of the diets. $P<0.05$ was considered statistically significant and a $P<$ 0.1 was considered as exhibiting a trend. Coefficient of variation (\%) for each parameter was determined by multiplying 100 with the ratio of standard deviation to mean.

\section{Results and Discussion}

Performance evaluation of the birds (Table-2) indicated that at 14 day, LW of the guar korma fed groups was inferior to the SBM fed ones (main effect of guar korma $\mathrm{P}=0.01$ ) and that mannanase supplementation did not revert this effect. Cumulative feed conversion deteriorated when SBM was partially replaced with guar korma (main effect of guar korma $P$ $=0.01$ ) and in this case too supplementation with $\beta$ mannanase failed to elicit any discernible beneficial effect (main effect of mannanase $\mathrm{P}>0.05$ ). It is worth noting that when SBM was partially replaced with guar korma, feed consumption increased (main effect of guar korma $\mathrm{P}=0.01$ ).

When comparisons were made between the diets, feed conversion was superior $(\mathrm{P}<0.05)$ in the $\mathrm{T} 1$ group when compared with the T2 group. However, there was no interaction between guar korma and $\beta$-mannanase $(\mathrm{P}>0.05)$. Keeping parity with the performance data, the PIS was negatively affected by supplementation of guar korma in diet (main effect of guar korma $\mathrm{P}=0.01$ ). There is ample evidence in the literature to show the negative effects of guar meal on broiler performance [5,23,24] although Tyagi [25] reported no adverse effects of guar korma on broiler performance even at levels as high as $10 \%$. The lower LW at day 14 was due to the fact that the growth depressing effect of guar meal is more pronounced in young chicks than in the older birds [26, 27]. It has been reported earlier that the high galactomannan content of guar meal increases digesta viscosity and suppresses nutrient digestibility to cause growth depression in broiler chicken [28]. In the present study the guar korma fed groups consumed significantly higher amount of feed and this was the reason for an inferior feed conversion in these groups. Interestingly, the effect of $\beta$-mannanase was more conspicuous when supplemented to the maize-SBM based control diet. Apparently, the activity of the $\beta$ mannanase used in this study was not sufficient to ameliorate the negative impact of the high amount of $\beta$ galactomannan in guar korma but could digest the same from SBM and liberate more energy by improving the digestibility of starch [15]. Looking into the data from another angle, it can be inferred that guar korma depressed the digestibility of starch and deprived the birds of the available energy [29]. As a compensatory mechanism, feed intake in guar korma fed birds increased. The galactomannan content of guar korma might have increased intestinal viscosity leading to impaired metabolism of major metabolites like starch, protein and glucose and this may be the plausible explanation for the poorer FCR in the T2 group. Leeds [30] reported that guar gum decreased 
Table-3. Effect of guar korma and $\beta$-mannanase on carcass traits (in $\mathrm{g} / \mathrm{kg}$ unless stated otherwise).

\begin{tabular}{|c|c|c|c|c|c|c|}
\hline \multirow[t]{2}{*}{ Attributes } & \multirow[t]{2}{*}{ Dressed weight } & \multicolumn{3}{|c|}{ Organ } & \multirow[t]{2}{*}{ Intestinal Weight } & \multirow[t]{2}{*}{ Intestinal Length $(\mathrm{cm})$} \\
\hline & & Liver & Spleen & Giblet & & \\
\hline \multicolumn{7}{|l|}{ Main effect of guar korma } \\
\hline $\begin{array}{l}\text { No guar korma } \\
+ \text { Guar korma } \\
\text { Main effect of mannanase }\end{array}$ & $\begin{array}{l}615.9 \\
614.2\end{array}$ & $\begin{array}{l}31.9 \\
31.7\end{array}$ & $\begin{array}{l}2.49 \\
2.72\end{array}$ & $\begin{array}{l}68.8 \\
7045\end{array}$ & $\begin{array}{l}77.5 \\
79.3\end{array}$ & $\begin{array}{l}184.6 \\
166.6\end{array}$ \\
\hline $\begin{array}{l}\text { No } \beta \text {-mannanase } \\
+\beta \text {-mannanase } \\
\text { Dietary effects }\end{array}$ & $\begin{array}{l}610.4 \\
619.4\end{array}$ & $\begin{array}{l}31.7 \\
31.9\end{array}$ & $\begin{array}{l}2.61 \\
2.60\end{array}$ & $\begin{array}{l}69.5 \\
69.7\end{array}$ & $\begin{array}{l}76.3 \\
80.4\end{array}$ & $\begin{array}{l}178.6 \\
172.7\end{array}$ \\
\hline T0 & 611.7 & 32.0 & 2.56 & 69.0 & 75.6 & $172.1^{\mathrm{a}}$ \\
\hline $\mathrm{T} 1$ & 620.1 & 31.8 & 2.42 & 68.6 & 79.4 & $161.1^{\mathrm{a}}$ \\
\hline T2 & 609.6 & 31.5 & 2.66 & 69.9 & 77.1 & $185.1^{\mathrm{b}}$ \\
\hline $\begin{array}{l}\text { T3 } \\
\text { Pooled SEM }\end{array}$ & $\begin{array}{c}618.7 \\
0.23\end{array}$ & 32.0 & $\begin{array}{l}2.78 \\
0.07\end{array}$ & $\begin{array}{c}70.9 \\
16\end{array}$ & 81.5 & $\begin{array}{c}184.2^{b} \\
176\end{array}$ \\
\hline $\begin{array}{l}\text { Coefficient of variation \% } \\
\text { Main effects ( } P \text { values) }\end{array}$ & $\begin{array}{l}0.23 \\
1.19\end{array}$ & 8.41 & 3.88 & 8.43 & 9.09 & 3.29 \\
\hline Guar korma & 0.71 & 0.88 & 0.17 & 0.61 & 0.65 & 0.01 \\
\hline Mannanase & 0.08 & 0.89 & 0.95 & 0.93 & 0.31 & 0.12 \\
\hline Guar korma x & & & & & & \\
\hline mannanase ( $P$ values) & 0.94 & 0.79 & 0.43 & 0.84 & 0.95 & 0.16 \\
\hline
\end{tabular}

Means bearing different superscripts in a column differ significantly $(P<0.05)$

T0, control diets containing maize and soybean meal; T1, T0 + ß-mannanase ( 32 million units/kg of feed); T2, Soybean meal replaced by guar korma at the rate of $20 \mathrm{~g} / \mathrm{kg}$ in the pre starter and $50 \mathrm{~g} / \mathrm{kg}$ in the starter and finisher diets; T3, T2 + $\beta$-mannanase ( 32 million units/ kg of feed)

glucose metabolism and retarded insulin secretion rates in swine. Possibly, suppression of insulin secretion impaired the intestinal uptake and utilization of glucose and amino acids and resulted in poor feed efficiency as reported earlier by Jackson [31].

Overall mortality did not show any regular pattern and ranged from $4 \%$ in the $\mathrm{T} 0$ group to $6.75 \%$ in the $\mathrm{T} 3$ group. Mortality was not related to the dietary treatments and there was no significant variation observed between the groups.

There was a subtle effect $(\mathrm{P}>0.05)$ of feeding guar korma and $\beta$-mannanase supplementation on carcass traits (Table-3). This is contradictory to the findings of Kamran [5] who reported decreased dressing percentage in birds fed with diets containing guar meal. Intestinal length was higher in the birds fed with guar korma (main effect of guar korma $\mathrm{P}=0.01$ ). Increased intestinal viscosity induced by the galactomannan of guar may be the reason for the longer GI tract [32].

\section{Conclusion}

It is concluded from the present study, that replacing SBM with guar korma at the rate of $20 \mathrm{~g} / \mathrm{kg}$ in the pre-starter and $50 \mathrm{~g} / \mathrm{kg}$ in starter and finisher diets with or without $\beta$-mannanase supplementation resulted in poorer feed conversion and inferior performance index score. Plausibly, the residual indigestible polysaccharides, such as pectin and $\beta$-galactomannan present in the guar korma increased the intestinal viscosity and inhibited the performance of broilers. In summary guar korma as a replacement for SBM at the levels tested in this study may not be beneficial under practical conditions and that further research is warranted to determine a more accurate level of inclusion of guar korma for better performance and carcass yields of birds.

\section{Authors' contributions}

AM designed the study and formulated the diet. SR contributed in acquisition of the experimental data and drafted the manuscript. SH analyzed and interpreted the results. SKS revised the manuscript for critical scientific corrections. All authors read and approved the final manuscript.

\section{Acknowledgements}

The authors express their gratitude to the Managing Director, Amrit Feeds Ltd, Kolkata, India for providing the facilities for conducting this experiment.

\section{Competing interests}

The authors declare that they have no competing interests. This research was carried out by the research and development department of Amrit Feeds Ltd., solely for the development of feed formulations of the company.

\section{References}

1. APEDA (2011) Agri Exchange Ready Reckoner Series Commodity: GUARGUM, http://agriexchange. apeda.gov.in. Accessed on January 18, 2013.

2. Hassan, S. M., El-Gayar, A. K., Cadwell, D. J., Bailey, C. A. and Cartwright, A. L. (2008) Guar meal ameliorates Eimeria tenella infection in broiler chicks. Veterinary Parasitology, 157: $133-138$.

3. Nagpal, M. L., Agrawal, O. P. and Bhatia, I. S. (1971) Chemical and biological examination of guar-meal (Cyampsis tetragonoloba L.). Indian Journal of Animal Science, 4: 283-293.

4. Lee, J. T., Conner-Appleton, S., Haq, A. U., Cartwright, A. and Bailey, C. (2004) Quantitative measurement of negligible trypsin inhibitor activity and nutrient analysis of guar meal fractions. Journal of Agricultural and Food Chemistry, 52: 6492-6495.

5. Kamran, M., Pasha, T. N., Mahmud, A. and Ali, Z. (2002) Effect of commercial enzyme (Natugrain) supplementation on the nutritive value and inclusion rate of guar meal in broiler rations. International Journal of Poultry Science, 1 (6): 167-173 
6. Anderson, J. O. and Warnick, R. E. (1964) Value of enzyme supplements in rations containing certain legume seed meals or gums. Poultry Science, 43:1091-1097.

7. Couch, J. R., Bakshi, Y. K., Ferguson, T. M., Smith, B. E. and Creger, C. R. (1967) The effect of processing on the nutritional value of guar meal for broiler chicks. British Poultry Science, 8:243-250.

8. Bochers, R. And Ackerson, C. W. (1950) The nutritive value of legume seeds. Journal of Nutrition, 41: 339-345.

9. Conner, S. (2002) Characterization of guar meal for use in poultry rations. Ph.D. Dissertation. Texas A\&M University, College Station, TX.

10. Vohra, P. and Kratzer, F. H. (1964) Growth inhibitory effect of certain polysaccharides for chickens. Poultry Science, 43:1164-1170.

11. Lee, J. T., Connor, S., Cartwright, A. and Bailey, C. (2005). Effects of Guar Meal By-Product with and without Bmannanase Hemicell on Broiler Performance. Poultry Science, 84: 1261-1267.

12. Salih, M. E., Classen, H. L., and Campbell, G. L. (1991) Response of chickens fed on hull-less barley to dietary $\beta$ glucanase at different ages. Animal Feed Science Technology, 33: 139-149.

13. Lee, J. T., Bailey, C. A. and Cartwright, A. L. (2003) Guar meal germ and hull fractions differently affect growth performance and intestinal viscosity of broiler chickens. Poultry Science, 82: 1589-1595.

14. Zangiabadi, H. R. and Torki, M. (2010) The effect of a $\beta$ mannanase-based enzyme on growth performance and humoral immune response of broiler chickens fed diets containing graded levels of whole dates. Tropical Animal Health and Production, 42: 1209-1217.

15. Ehsani, M. and Torki, M. (2010) Effects of dietary inclusion of guar meal supplemented by $\beta$-mannanase on performance of laying hens, egg quality characteristics and diacritical counts of white blood cells. American Journal of Animal and Veterinary Sciences, 5 (4): 237-243.

16. McNaughton, J. L., Hsiao, H., Anderson, D. and Fodge, D. W. (1998) Corn/soy/fat diets for broilers, $\beta$-mannanase and improved feed conversion. Poultry Science, 77(Suppl. 1): 153.

17. Daskiran, M., Teeter, R. G., Fodge, D. W. and Hsiao, H. Y. (2004) An evaluation of endo- $\beta$-D-mannanase (Hemicell) effects on broiler performance and energy use in diets varying in $\beta$-mannan content. Poultry Science, 83: 662-668.

18. Cobb (2004) Cobb 400 Broiler Management Guide. CobbVantress Inc. Siloam Springs, Arkansas.

19. A.O.A.C. (2005) Official Methods of Analysis. $18^{\text {th }}$ Ed. Association of Official Analytical Chemist, Benjamin
Frankin Station, Washington, DC.

20. National Research Council. (1994) Nutrient Requirements of Poultry. 9th Rev. Edition. National Academic Press, Washington, DC.

21. BIS. (1975) Bureau of Indian Standards (IS 7874: 1975). Methods of tests for animal feeds and feeding stuffs: Part 2 Minerals and trace elements.

22. BIS. (2007) Bureau of Indian Standards (IS 1374: 2007). Poultry Feeds-Specification. (Fifth Revision).

23. Brahma, T. C. and Siddiqui, S. M. (1978) A preliminary study on the utilization of toasted guar meal in broiler rations. Indian Poultry Gazette, 62: 133-138.

24. Larhang, R. A. and Torki, M. (2011) Evaluating Performance of Broilers Fed Guar Meal-incuded diet Supplemented by Enzyme. Researches of the first international conference (Babylon and Razi Universities): 243-247.

25. Tyagi, P. K., Mandal, A. B. and Tyagi, P. K. (2011) Utilization of roasted guar (Cyamopsis tetragonoloba) korma in the diet of broiler chickens. Indian Journal of Poultry Science, 46: 326-329.

26. Verma, S. V. S. and McNab, J. M. (1982) Guar meal in diets for broiler chickens. British Poultry Science, 23: 95-105.

27. Lee, J. T., Bailey, C. A. and Cartwright, A. L. (2003) Bmannanase ameliorates viscosity-associated depression of growth in broiler chickens fed guar germ and hull fractions. Poultry Science, 82: 1925-1931.

28. Almirall, M., Francesch, M., Perez-Vendrell, A. M., Brufau, J. and Esteve-Garcia, E. (1995) The difference in intestinal viscosity produced by barley and B-glucanase alter digesta enzyme activities and ileal nutrient digestibilities more in broiler chicks than in cocks. Journal of Nutrition, 125: 947-955.

29. Edwards, C. A., Johnson, I. T. and Read, N. W. (1988) Do viscous polysaccharides slow absorption by inhibiting diffusion or convection. European Journal of Clinical Nutrition, 42: 306-312.

30. Leeds, A. R., Kang, S. S., Low, A. G. and Sambrook, I. E. (1980) The pig as a model for studies on the mode of action of guar gum in normal and diabetic man. The Proceeding of the Nutrition Society, 39: 44A.

31. Jackson, M. E., Fodge, D. W., Hsiao, H. Y. (1999) Effects of $\beta$-mannanase in corn-soybean meal diets on laying hen performance. Poultry Science, 78:1737-1741.

32. Smits, C. H. N., Veldman, A., Verstegen, M. W. A. and Beynen, A. C. (1997) Dietary carboxymethylcellulose with high instead of low viscosity reduces macronutrient digestion in broiler chickens. Journal of Nutrition, 127: 483-487. 